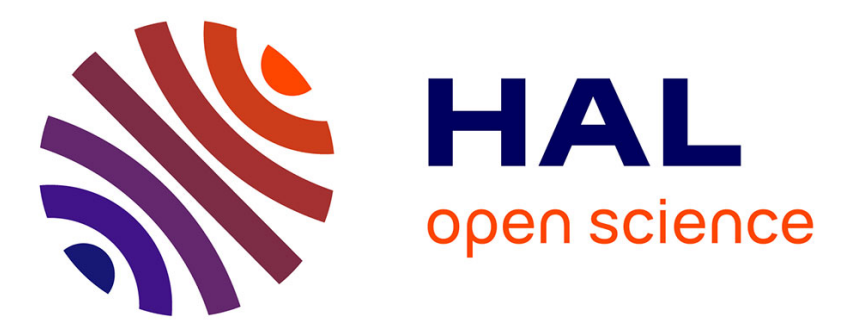

\title{
In situ study of magmatic processes: a new experimental approach
}

\author{
Charlotte Gondé, D. Massare, Hélène Bureau, Caroline Martel, Michel \\ Pichavant, Roberto Clocchiatti
}

\section{- To cite this version:}

Charlotte Gondé, D. Massare, Hélène Bureau, Caroline Martel, Michel Pichavant, et al.. In situ study of magmatic processes: a new experimental approach. High Pressure Research, 2006, 26, pp.243-250. 10.1080/08957950600881512 . hal-00081654

\section{HAL Id: hal-00081654 \\ https://hal-insu.archives-ouvertes.fr/hal-00081654}

Submitted on 9 Nov 2006

HAL is a multi-disciplinary open access archive for the deposit and dissemination of scientific research documents, whether they are published or not. The documents may come from teaching and research institutions in France or abroad, or from public or private research centers.
L'archive ouverte pluridisciplinaire HAL, est destinée au dépôt et à la diffusion de documents scientifiques de niveau recherche, publiés ou non, émanant des établissements d'enseignement et de recherche français ou étrangers, des laboratoires publics ou privés. 


\title{
In situ study of magmatic processes:
}

\section{a new experimental approach}

\author{
C. GONDÉ ${ }^{1.2}$, D. MASSARE ${ }^{1}$, H. BUREAU ${ }^{1}$, C. MARTEL $^{2}$, M. PICHAVANT $^{2}$, R. CLOCCHIATTI $^{1}$ \\ ${ }^{1}$ Laboratoire Pierre Süe - CEA/CNRS - CEA Saclay - 91191 Gif/Yvette \\ ${ }^{2}$ Institut des Sciences de la Terre d'Orléans - CNRS - 45071 Orléans
}

\begin{abstract}
-
We present an internally heated autoclave, modified in order to allow in situ studies at pressure up to $0.5 \mathrm{GPa}$ and temperature up to $1000^{\circ} \mathrm{C}$. It is equipped with transparent sapphire windows, allowing the observation of the whole experiment along the horizontal axis. In the experimental cell the sample is held between two thick transparent plates of sapphire or diamond, placed in the furnace cylinder. The experimental volume is about 0.01 $\mathrm{cm}^{3}$. Video records are made during the whole experiment.

This tool is developed mainly to study magmatic processes, as the working pressures and temperatures are appropriate for subvolcanic magma reservoirs. However other applications are possible such as the study of subsolidus phase equilibria as we have used well known phase transitions, such as the system of AgI, to calibrate the apparatus with respect to pressure and temperature.

The principle of the apparatus is detailed. Applications are presented such as studies of melt inclusions at pressure and temperature and an in situ study of magma degassing through the investigation of nucleation and growth processes of gas bubbles in a silicate melt during decompression.
\end{abstract}

Keywords - in situ - transparent autoclave - high pressure, high temperature - phase transitions - melt inclusions studies - silicate melts - bubble growth - decompression 


\section{Introduction}

Understanding the physical and geochemical processes occurring in the deep Earth is one of the fundamental tasks of research in the experimental petrology community. This requires experimental tools able to create confining pressure $(\mathrm{P})$ and temperature $(\mathrm{T})$ conditions relevant for such processes, such as cold-seal pressure vessels, internally heated pressure vessels or piston cylinders. Usually with such apparatuses, the experimental charge is quenched at room conditions after equilibrium has been reached in order to be characterized. However, it has been shown that some processes are not preserved at room conditions; the experimental quench induces fundamental changes in the structure and chemistry of the sample.

The in situ approach, the study of processes at pressure and temperature in real time, has been developed since decades by the community of diamond anvil cell (DAC) experimentalists, initially because the use of diamond anvils was the only issue to reach the high pressures of the deep Earth mantle and core, but also because diamonds are transparent and allow the in situ characterization of the studied processes either by observation or by in situ spectroscopy (Raman, X-Rays, Infrared...). During the 90's, DACs have been developed to be applied to low or moderate pressures (a few hundred of $\mathrm{Pa}$ to $2 \mathrm{GPa}$ ) and magmatic temperatures (up to $1000^{\circ} \mathrm{C}$ ) by Bassett en co-workers [1], making accessible in situ studies involving magmas or silicate melts [i.e. 2-5]. However, the use of Bassett Hydrothermal Diamond anvil cells (HDAC) presents a few limitations making difficult the investigation of very shallow high-temperature magmatic processes.

The first limitation of HDAC experiments is due to the pressure medium which is water. Therefore, any study should involve aqueous and/or water saturated systems. Because experimental volcanology studies require very accurate measurements of pressure in the range room pressure $-0.5 \mathrm{GPa}$, to investigate pre-eruptive phenomena (crystal growth, degassing processes, chemical partitioning etc...). The second limitation is the pressure determination. Actually, in HDAC pressure is calculated using equation of states of aqueous fluids after the experiments. Therefore it is not always accurately determined, more especially when complex systems such as hydrous silicate melts are studied [6]. Therefore, whereas the use of HDAC has definitely improved our knowledge of magmatic phase equilibrium occurring in the mantle and deep crust, the shallow crust will still be a forbidden domain for such in situ investigations, as long as the pressure measurement will still not be possible for pressures less than a hundreds of MPa.

Two options need to be explored: the accurate measurement of low pressures in HDAC (see Bureau \& al., this volume) or/and the development of new tools, able to perform studies at low pressures and magmatic temperatures. 
Here we present an internally heated pressure vessel (LPS; Saclay, France), able to reach pressures up to $0.5 \mathrm{GPa}$ and temperatures up to $1000^{\circ} \mathrm{C}$ and allowing an in situ approach offering the possibility to observe the samples and to record the experiments. A calibration of the vessel in pressure and temperature together with two applications are presented.

\section{The apparatus}

\subsection{The vessel}

The vessel, shown schematically in Figure 1, consists of a thick-walled cylinder made of high mechanical properties (steel $819 \mathrm{AW}$ ). It has an internal diameter of $50 \mathrm{~mm}$ and an external diameter of $150 \mathrm{~mm}$. A cooling water system made by a rubber pipe winding wrapping the exterior of the vessel, maintains the body at low temperature when the furnace is functioning. This winding is protected by steel plates, fixed on the body. The vessel is sealed by Bridgman-type closure heads and joints and is working horizontally. Along the horizontal axis, transparent sapphire windows on the closure heads permit the observation of the sample under high pressure and temperature. The sample can be observed in a microscope coupled with an acquisition system.

The pressure medium is Argon. Pressure is obtained with a two stage diaphragm compressor (one head at $0.1 \mathrm{GPa}$ and the other at $0.35 \mathrm{GPa}$ ) alimented with compressed air. The pressure in the system is measured by a pressure gauge with a precision of $\pm 2 \mathrm{MPa}$. The maximal working pressure and temperature are about $0.5 \mathrm{GPa}$ and $1000^{\circ} \mathrm{C}$ respectively.

\subsection{The high pressure cell}

The present section describes the high pressure cell of the internally heated vessel (Figure 2). This cell consists of closure heads, a furnace, and a sample holder. The modus operandi necessary to perform an experiment is described at the end of this section.

\section{- The closure heads}

The closure heads are Bridgman-type [7], but they are pierced on the top to hold transparent circular sapphire windows (8-12 $\mathrm{mm}$ diameter and $8 \mathrm{~mm}$ thickness) for sample observation. 
The lower closure head contains two ports for the thermocouple leads, four ports for the furnace supply and one hole for the gas. All leads are electrically isolated form the steel closure head. Bridgman-type joints for sealing the vessel are alternating Teflon, rubber and Teflon rings.

\section{- The furnace}

The furnace (Figure 3) consists of a $5 \mathrm{~mm}$ diameter internal alumina tube wrapped in a tungsten winding, fixed on the tube with a ceramic resistant to high temperatures. Fine Inox foils are placed around the winding to minimize gas convection and thermal inertia. The $\mathrm{W}$ winding is connected to the electrical lead of the supply by $\mathrm{Cu}$-Be cones (fig 2.10). The furnace is fixed on both sides of the closure heads with pyrophyllite rings, resistant to high temperatures and to compression.

Working temperatures of thousand degrees are commonly attained. They are measured using a S-type thermocouple with a precision of $\pm 1^{\circ} \mathrm{C}$.

\section{- The sample holder}

The sample holder is made with a stabilized sapphire tube, $22 \mathrm{~mm}$ long and $4 \mathrm{~mm}$ diameter (see figure 3). At the top of the upper tube, a head in Pt-PtRh with a hole filled by a sapphire window forms a cavity in which we place the sample. The maximal experimental volume of the sample corresponds to a ring of $4 \mathrm{~mm}$ diameter and about 3-4 $\mathrm{mm}$ thick. The upper sapphire tube is inserted in the furnace, in contact with the thermocouple placed on the lower sapphire tube.

\section{- Procedure}

Before an experiment, the sample is placed in the sample holder which is inserted in the furnace. The vessel is hermetically closed sealing the closure heads and closure nuts. Argon is introduced and compressed up to the desired value pressure before the furnace is started. The furnace heats the sample with a typical rate of $15^{\circ} \mathrm{C} / \mathrm{min}$, depending on the pressure. During the experiments, an optical fibre lightens the sample through the different sapphire windows and the sample is observed through the objective. A numerical camera, linked with an acquisition system, is placed in front of the objective and permits the observation of the sample and the video-record of the experiment. The three key parameters of each experiment (pressure, temperature, time) are recorded together with the movies of the experiments. 


\section{Calibrations}

Measurements of phase transition compounds such as Silver Iodide (AgI) have been performed at pressure and temperature. Therefore pieces of AgI have been loaded in the sample chamber and the the $\beta-\alpha$ or $\alpha-\beta$ phase transitions have been characterized. Results are presented in figure 4 . The runs have been performed at a defined pressure while temperature was either increased (blue curve) or decreased (green curve) to observe the phase transitions. These transitions were instantaneous; the whole process lasted typically 1-2 seconds. The experiments were made at low temperature (up to $150^{\circ} \mathrm{C}$ ) and middle pressure (up to $0.3 \mathrm{GPa}$ ). We observe a perfect agreement between the theoretical values and our data (blue diamonds, fig $4 \mathrm{~b}$ ), confirming that the temperature gradient in the sample chamber is negligible. An hysteresis phenomena is detected for the transitions occurring with decreasing $\mathrm{T}$ (triangle), which is current for these types of experiments [e.g. 9].

Measurements of the $\alpha-\beta$ transition of quartz at pressure and temperature through the in situ optical studies have been performed with this vessel in the range 20-470 $\mathrm{MPa}, 570-690^{\circ} \mathrm{C}$ [9]. The experimental results have shown that this transition can be used as an internal standard of temperature for the autoclave.

\section{Applications}

\section{- Melt inclusions studies}

This vessel was first devoted to the study of fluid and magmatic inclusions trapped in minerals at pressure and temperature [10]. Melt and fluid inclusions are tiny droplets of magma (fluid and/or silicate melt and/or crystals) trapped in minerals (olivine, plagioclases, quartz...) during their growth either in magma chambers or conduits, or in hydrothermal systems (fig. 5). Therefore they represent precious records of the melt or fluid composition and history at the time of their trapping (providing no modification occurred in the inclusion after entrapment). Micro-thermometry investigations are performed to determine temperature of either phase transformation in the case of fluid inclusions or 
disappearance of the melt inclusion bubble. One major concern of the micro-thermometry experimental approach is the effect of confining pressure on the homogenization temperature of the inclusions. Therefore [10] performed homogenization experiments at pressure and temperature in the range $0.1-400 \mathrm{MPa}$ and $200-850^{\circ} \mathrm{C}$ on saline aqueous inclusions trapped in hydrothermal quartz and in magmatic inclusions of rhyolitic composition trapped in volcanic sanidines. The effect of pressure on the temperature of homogenization of fluid and melt inclusions was found to be significant (ex. $70^{\circ} \mathrm{C} / 100 \mathrm{MPa}$ in the temperature range of $560-850^{\circ} \mathrm{C}$ for rhyolitic melt inclusions). These results show that the pressure effect should not be neglected during micro-thermometry investigations.

\section{- Magma degassing studies}

In volcanology, the exsolution of gas during the ascent of magma to the surface is one of the key parameters influencing the dynamics of volcanic eruptions. Therefore, in order to test the numerical models established to understand magma vesiculation [ex.11, 12], several experimental studies have been performed [ex. 13-16]. Usually the ascent of magma is experimentally simulated in autoclaves by decompression experiments at a constant temperature, the samples studied after quench. However this post-mortem characterization is limited because nucleation, growth and coalescence of the gas bubbles are not directly observed, but only the resulting vesiculated glasses.

A few in situ studies have been made at temperature but at room pressure [17-19], but they are not applicable directly to natural systems. Recently, a direct observation of the vesiculation process at temperature and pressure conditions was made by [20] in a Bassett HDAC. Bubble growth was studied with respect to pressure, temperature and time, during decompression. Although this study promotes the advantages of the in situ observation (i.e. real-time bubble growth, nucleation and coalescence), the experimental conditions were not relevant to conduit-flow processes (drastic drop of temperature, too high pressures). Therefore, our efforts have been devoted to improve the in situ characterization of bubble nucleation and growth, by modifying the vessel in order to perform experimental decompression at constant temperature with a direct observation of the whole process.

Vesiculation experiments have been made with an hydrous synthetic glass of haplogranitic composition $\left[\mathrm{SiO}_{2}=78.6 \mathrm{wt} \%, \mathrm{Al}_{2} \mathrm{O}_{3}=12.5 \mathrm{wt} \%, \mathrm{Na}_{2} \mathrm{O}=4.6 \mathrm{wt} \%, \mathrm{~K}_{2} \mathrm{O}=4.2 \mathrm{wt} \%\right.$, hydrated to 6.3 $\mathrm{wt} \%$ in an internally heated pressure vessel (ISTO, Orléans, France) at $1200^{\circ} \mathrm{C}$ and $0.2 \mathrm{GPa}$. Doubly polished pieces of glass of about $500 \mu \mathrm{m}$ thick are placed in the sample holder, between the two diamond transparent windows. When the desired temperature and pressure are reached, the silicate melt is manually decompressed. The nucleation and growth of water bubbles in the melt are videorecorded (figure 6). Movies and images are then analyzed to describe the processes. Comparison will be made with other experimental results and numerical models. 


\section{Conclusion}

Internally heated pressure vessels applied to in situ investigation at pressure and temperature represent valuable tools to investigate chemical and physical processes in real time. They can be applied, either in the field of experimental petrology and volcanology (magma degassing, magma crystallization, study of melt and fluid inclusions) or in the field of experimental mineralogy (optical determination of the pressures and temperatures of phase transitions). They offer a complementary approach with the Hydrothermal Diamond Anvil Cells as they permit the in situ investigation of processes that occur at very shallow depths with accurate pressure measurements. Compared to HDAC, such vessels allow the use of large volume experimental charge and permit decompressions at constant temperatures.

\section{Acknowledgments}

We would like to thank Gérard Hamel, Stéphane Lequien, Christian Bettoni, Pascal Lhénoret, Marc Billon, François Saillant and Eddy Foy for their kind assistance. We acknowledge Rémi Champallier for his support during sample preparation.

\section{References}

[1] Bassett W.A., Shen A.H., Bucknum M., Chou I.M Rev. Sci. Instrum. 64 (8), pp. 23402345 (1993).

[2] Shen A.H., Keppler H. Am. Min. 80, pp. 1335-1338 (1995).

[3] Bureau H., Keppler H. Earth Planet. Sci. Letters 165, pp. 187-196 1999).

[4] Sowerby J.R., Keppler H. Contrib. Mineral. Petrol. 143, pp. 32-37 (2002).

[5] Audétat A., Keppler H. Earth Planet. Sci. Lett. 232, pp. 393-402 (2005).

[6] Saul A., Wagner W. J. Phys. Chem. Ref. Data 18 (4), pp. 1537-1564 (1989).

[7] Bridgman P.W. The physics of high pressure, Dover Ed. (1958).

[8] Mellander B.E., Lunden A., Friesel M., Solid State Ionics 5, pp. 477-480 (1981).

[9] Massare D., Syfosse G., Clocchiatti R. C.R. Acad. Sci. Paris 307 (II), pp. 375-378 (1988).

[10] Massare D., Clocchiatti R. C.R. Acad. Sci. Paris 305 (II), pp. 1207-1210 (1987).

[11] Proussevitch A.A., Sahagian D.L., Anderson A.T. J. Geophys. Res. 78 (B12), pp. 22 283-22 307 (1993).

[12] Toramaru A. J. Geophys. Res. 100 (B2), pp. 1913-1931 (1995).

[13] Hurwitz S., Navon D. Earth Planet. Sci. Lett. 122, pp. 267-280 (1994).

[14] Lyakhovsky V., Hurwitz S., Navon O. Bull. Volcanol. 58, pp. 19-32 (1996). 
[15] Gardner J.F., Hilton M., Carroll M.R. Earth Planet. Sci. Lett. 168, pp. 201-218 (1999).

[16] Mourtada-Bonnefoi C.C., Laporte D. Geophys. Res. Lett. 26 (23), pp. 3505-3508 (1999).

[17] Bagdassarov N.S., Dingwell D.B., Wilding M.C. Bull. Volcanol. 57, pp. 587-601 (1996).

[18] Navon O., Chekhmir A., Lyakhovsky V. Earth Planet. Sci. Lett. 160, pp. 763-776 (1998).

[19] Liu Y., Zhang Y. Earth Planet. Sci. Lett. 181, pp. 251-264 (2000).

[20] Martel C., Bureau H. Earth Planet. Sci. Lett. 191, pp. 115-127(2001). 


\section{Figures}

Figure 1 - Schematic view of the internally heated pressure vessel system : [1] closure nuts; [2] Bridgman-type joints ; [3] closure heads ; [4] transparent sapphire windows ; [5] furnace ; [6] sample ; [7] cooling water system

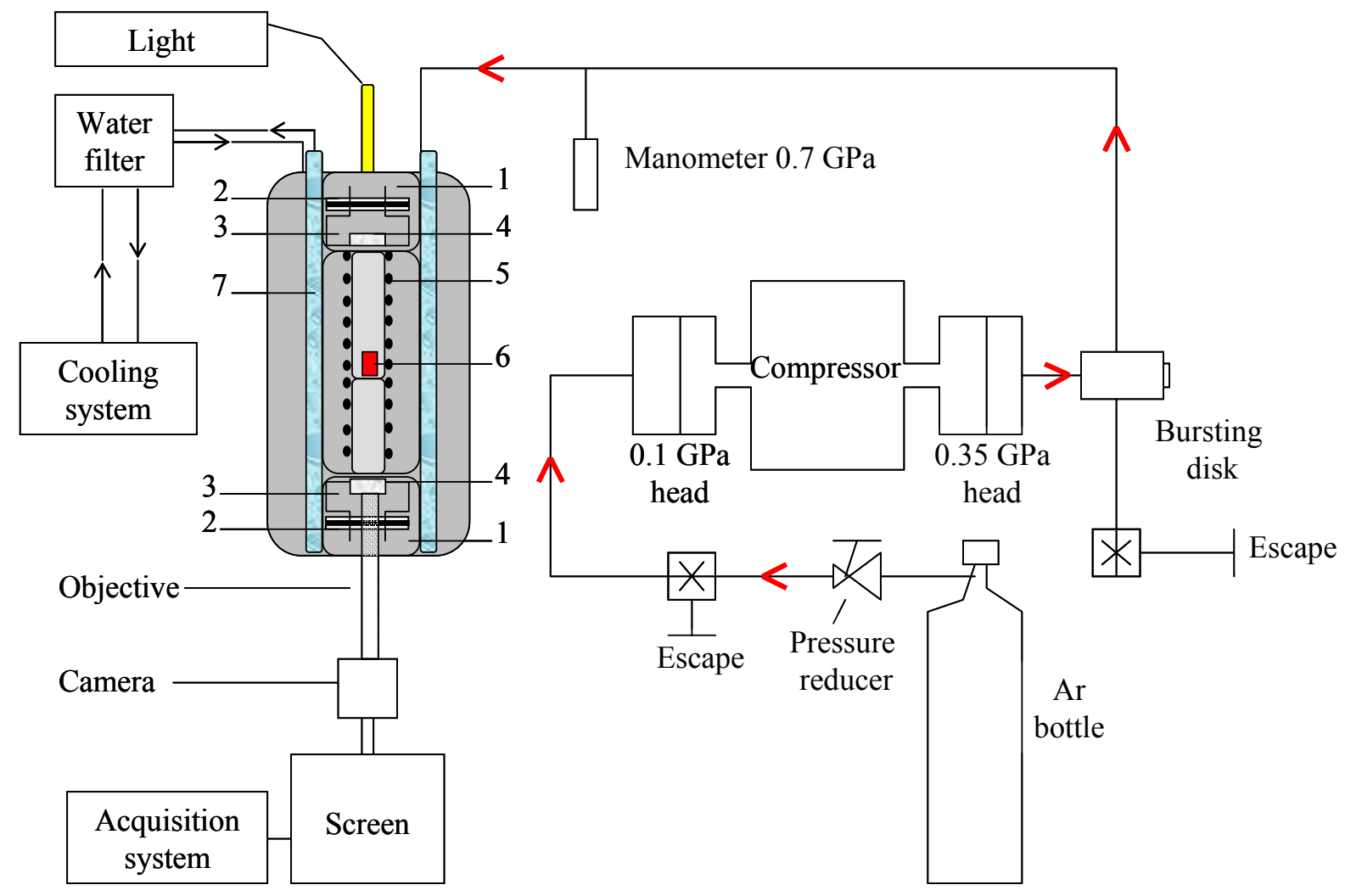

Figure 2 - Schematic view of the pressure cell : [1] seal (Bridgman-type joints); [2] closure heads ; [3] sapphire windows ; [4] pyrophyllite ; [5] sapphire bars ; [6] Inox foils ; [7] thermocouple ; [8] W winding (furnace) ; [9] Sample ; [10] electrical contacts (furnace supply) ; [11] gas supply 


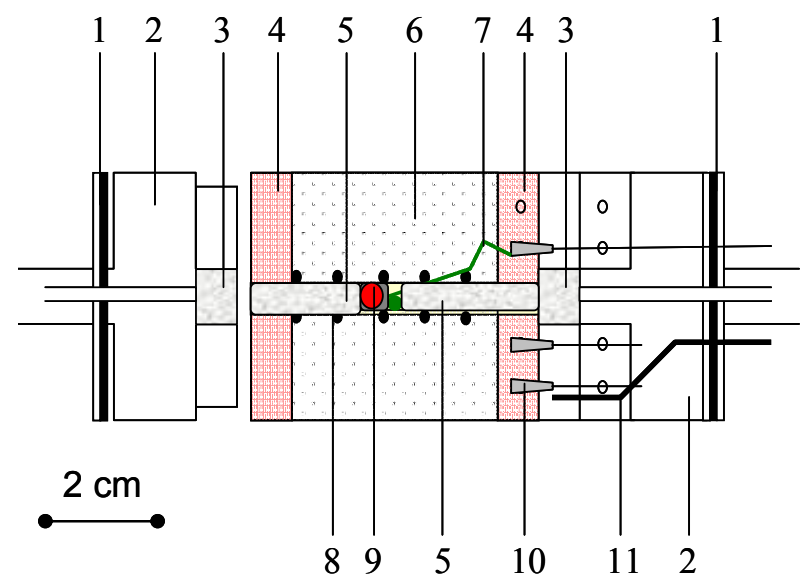

Figure 3 - Schematic view of the furnace : [1] pyrophyllite rings ; [2] furnace ; [3] W winding ; [4] A1 foils ; [5] thermocouple - and of the sample holder : [6] a. upper sapphire tube - b. lower sapphire tube ; [7] Pt-PtRh head ; [8] sample ; [9] sapphire window

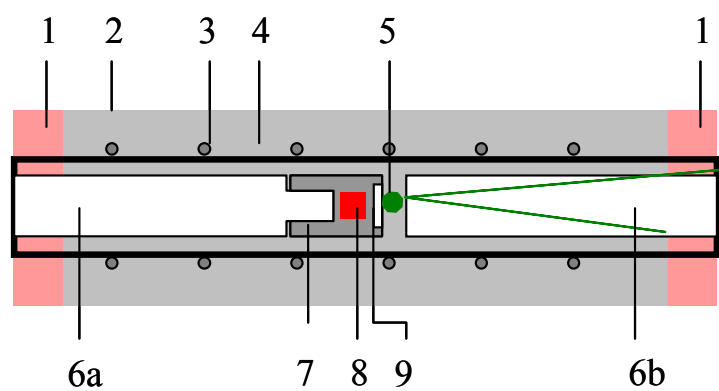

Figure 4 : Pressure versus Temperature diagram of AgI stability phase after [8]. The red squares correspond to the theoretical points after obtained by two methods, electrical conductivity and differential scanning calorimetry measurements. Our experimental results are as follows : blue diamonds phase transition pressure in temperature during the increase of temperature ; green triangles phase transition pressure in temperature during the decrease of temperature.

The errors reported in the diagram are the sum of uncertainties due to the pressure and temperature measurements together with the uncertainties due to the lecture of pressure and temperature during the phase transition. 


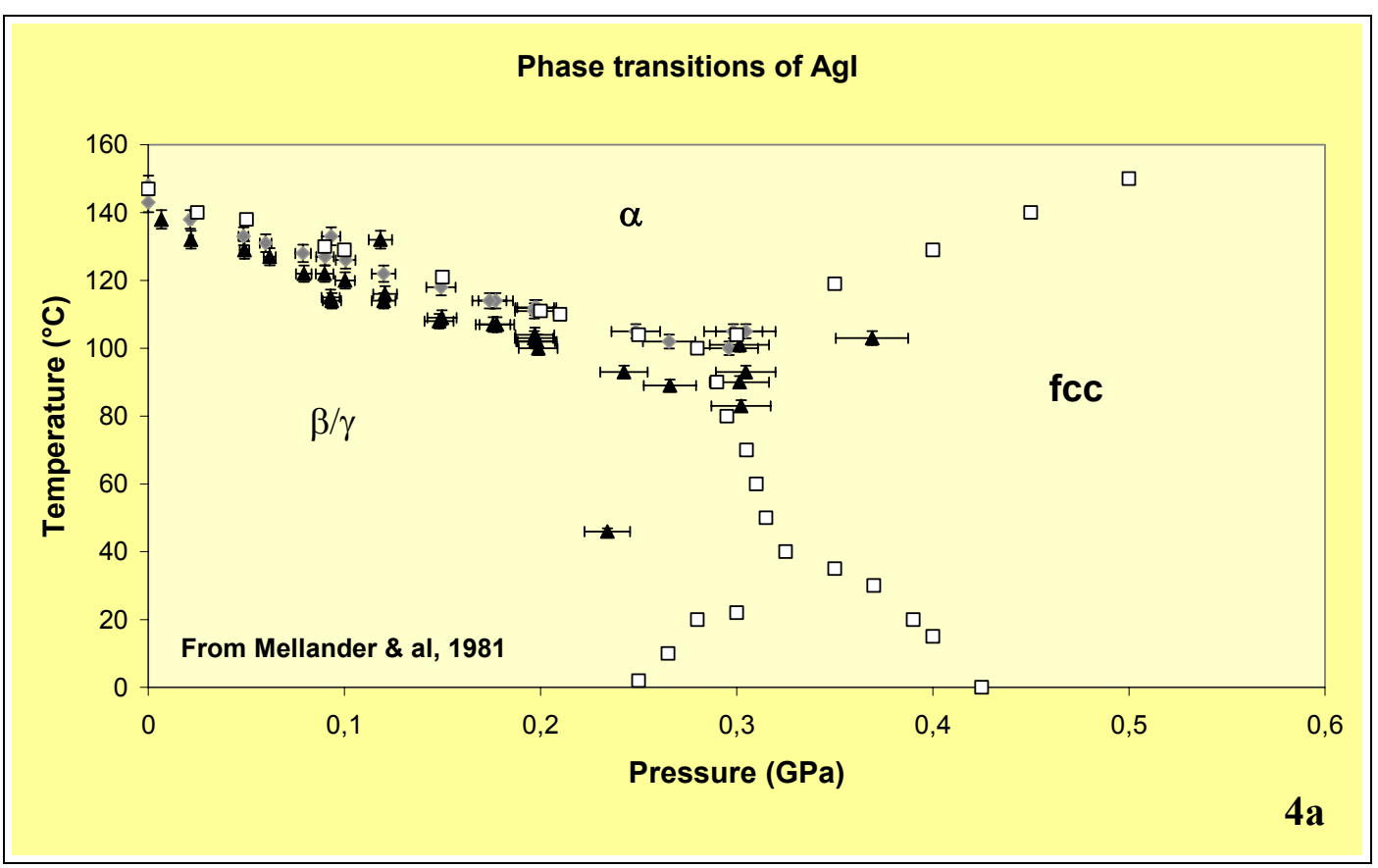

$\square$ Theoretical points of Mellander et al, 1981

$\checkmark \mathrm{P}, \mathrm{T}$ experimental points when increasing $T$ $\Delta \mathrm{P}, \mathrm{T}$ experimental points when decreasing $\mathrm{T}$

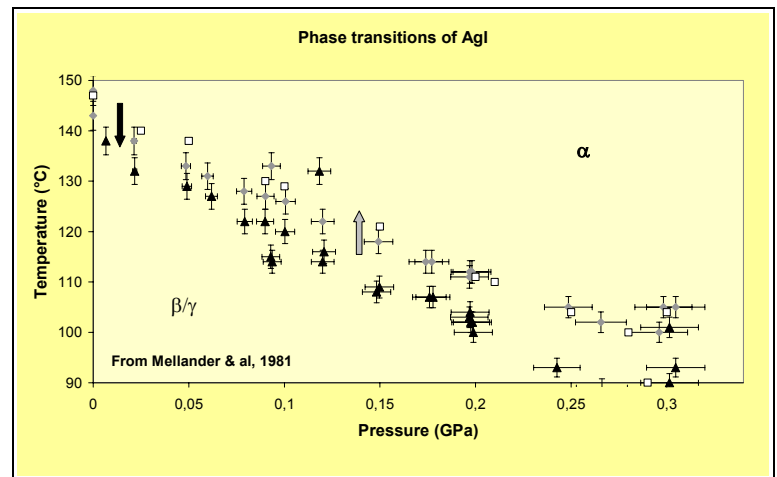

4b

Figure 5 - Picture of melt inclusion $(\sim 110 \mu \mathrm{m})$ in sanidine, demixion of the fluid phase in the melt.

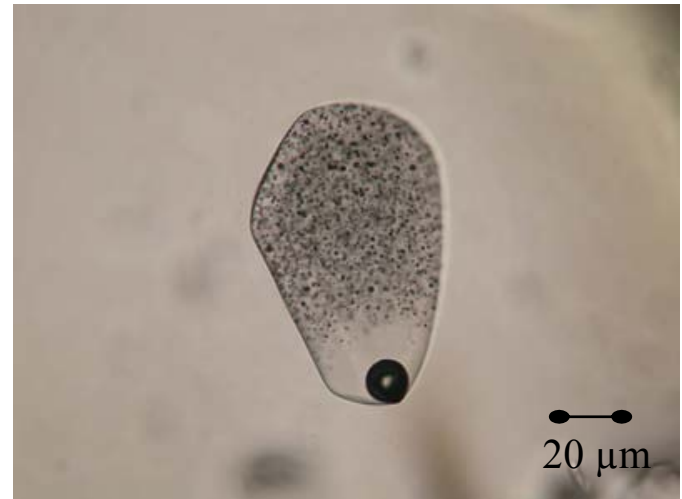


Figure 6 - Picture of the glassy sample observed after decompression from $850^{\circ} \mathrm{C}-0.3 \mathrm{GPa}$, Evidencing of the vesiculation process (diameter of bubbles about $50 \mu \mathrm{m}$ )

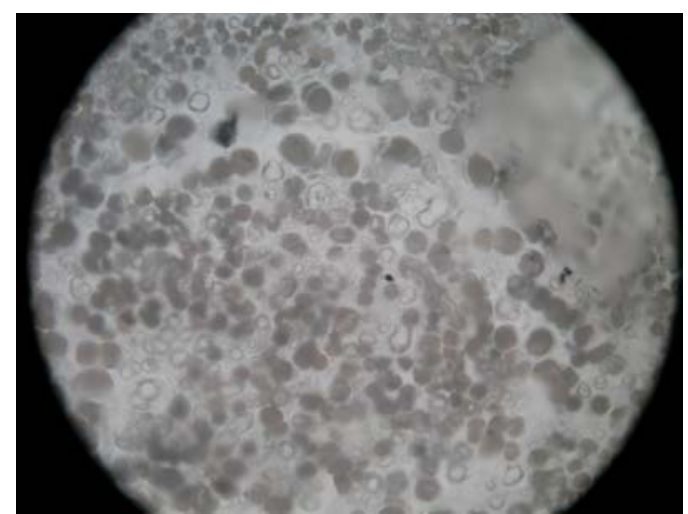

